\title{
ANALISA UNJUK KERJA MOTOR BAKAR BERBAHAN BAKAR BIOGAS TERMURNIKAN BERBASIS ABSORBER $\mathrm{Fe}_{2} \mathrm{O}_{3}$
}

\author{
Rudy Sutanto, Ida Bagus Alit, Nurchayati \\ Jurusan Teknik Mesin F.T. Universitas Mataram \\ Jl. Majapahit No.62 Mataram, Nusa Tenggara Barat, 83125 \\ Email : r_sutanto10@yahoo.com
}

\begin{abstract}
Long-term aim of this research is to obtain a biogas what the renewable natural gas quality and can be used to fuel an electric generator to support the availability of electricity in the region of small islands. Specific targets to be achieved is to determine whether the binding of $\mathrm{H}_{2} \mathrm{~S}$ in biogas can raise engine peformance of the machine, information technology and the active materials so comprehensive to absorb hydrogen sulfide gas as materials of the textbook writing and articles for national journals.

This research will be conducted a biogas testing in the engine performance, seen from the engine rotation $(1500,2500,3500$ and $4500 \mathrm{rpm})$ of the electric power generated and subtlety spin machine (braking force, fuel consumption) in both the before purified biogas and biogas has been purified.

Results of the research that has been conducted in both the before purified biogas and biogas has been purified on peformance engine that does not change significantly for the better performance of the engine torque, effective power and fuel consumption (biogas) to treat a wide variety. Effect of reduction of $\mathrm{H}_{2} \mathrm{~S}$ contained in the biogas no significant effect on engine performance but are more inclined towards corrosive metal material.

Keywords: biogas, performance, torque, effective power
\end{abstract}

\section{PENDAHULUAN}

Salah satu kendala pembangunan di kawasan pulau-pulau kecil adalah dalam ketersediaan sarana listrik, karena energi listrik ini sangat menunjang pengembangkan perekonomian di kawasan ini, salah satunya dalam mensupport pengembangkan pabrik es dan coldstrogae. Akibat semakin langkanya sumber energi minyak bumi dan semakin tingginya harga minyak mentah dunia, hal ini menjadikan kendala utama PLN dalam mendistribusikan jaringan listrik di kawasan tersebut. Sehingga hal ini menuntut dilakukannya penelitian secara menyeluruh terhadap pemanfaatan energi alternatif yang ramah lingkungan untuk bahan bakar generator listrik, dan sebagai bahan pertimbangan yang sangat penting adalah pemanfaatan kekayaan alam yang ada di kawasan pulau kecil tersebut sebagai sumber energi alternatif yang akan dikembangkan.

Salah satu energi alternatif yang sekarang sedang dikembangkan adalah energi yang berasal dari bahan - bahan organik, hal ini dikarenakan senyawa organik tersebut tergolong energi yang dapat diperbarui. Keberadaaan bahan - bahan organik tersebut mudah didapat dan terjamin kontinuitasnya, selain itu yang terpenting bahan - bahan organik tersebut ramah lingkungan. Hal ini yang menjadi faktor utama keberadaan bahan - bahan organik dipertimbangkan sebagai energi masa depan dalam rangka mewujudkan teknologi hijau (green technology). Biogas merupakan salah satu produk dari teknologi hijau yang sekarang sedang dikembangkan. Hal ini dikarenakan gas yang dihasilkan dari proses biologis (anaerobic digester) mampu menghasilkan gas - gas seperti $\mathrm{CH}_{4}, \mathrm{CO}_{2}$, $\mathrm{H}_{2} \mathrm{~S}, \mathrm{H}_{2} \mathrm{O}$ dan gas - gas lain. Dalam hal ini tentu saja yang dimanfaatkan adalah gas metana $\left(\mathrm{CH}_{4}\right)$, karena $\mathrm{CH}_{4}$ memiliki nilai kalor/panas yang dapat digunakan sebagai bahan bakar. Degradasi secara mikrobiologi dari bahan - bahan organik dalam lingkungan anaerob hanya dapat dilakukan oleh mikroorganisme yang mampu memanfaatkan molekul selain oksigen sebagai akseptor hidrogen. Dekomposisi anaerob menghasilkan biogas yang terdiri dari metana (50 - $70 \%)$, karbondioksida (25 - $45 \%$ ) dan sejumlah kecil hidrogen, nitrogen, hydrogen sulfida.

Kemurnian $\mathrm{CH}_{4}$ yang dihasilkan dari biogas tersebut menjadi pertimbangan yang sangat penting, dikarenakan berpengaruh terhadap nilai kalor / panas yang dihasilkan. Sehingga $\mathrm{CH}_{4}$ yang dihasilkan perlu 
dilakukan pemurnian terhadap impuritasimpuritas yang lain. Impuritas yang berpengaruh terhadap nilai kalor/panas adalah $\mathrm{H}_{2} \mathrm{~S}$, keberadaan $\mathrm{H}_{2} \mathrm{~S}$ dalam gas $\mathrm{CH}_{4}$ sangat tidak diinginkan, dikarenakan semakin tinggi kadar $\mathrm{H}_{2} \mathrm{~S}$ dalam $\mathrm{CH}_{4}$ maka akan semakin menurunkan nilai kalor $\mathrm{CH}_{4}$ dan sangat mengganggu dalam proses pembakaran. Hal ini menyebabkan kemurnian $\mathrm{CH}_{4}$ menjadi rendah.

\section{TINJAUAN PUSTAKA}

Pengolahan jerami padi sebagai bahan baku pembuatan biogas, adapun penelitian dilakukan dengan membandingkan kualitas dan kuantitas biogas yang dihasilkan dari jerami biasa $(A)$ dengan biogas yang dihasilkan dari jerami yang difermentasi (AA) dan dengan biogas yang dihasilkan dari jerami yang dicampur kotoran sapi (BB). Hasil penelitian menunjukkan bahwa produksi biogas paling banyak yang diukur selama empat minggu dihasilkan oleh komposisi AA sebanyak 164.774 liter, kemudian pada komposisi BB sebanyak 146.176 liter, dan produksi biogas paling sedikit dihasilkan oleh komposisi A sebanyak 102.01 liter. Sedangkan daya yang diserap air paling besar pada uji aplikasi dihasilkan oleh komposisi BB dengan daya sebesar 672.87 watt, kemudian komposisi AA dengan daya sebesar 608.41 watt, dan daya yang paling kecil dihasilakn oleh komposisi A dengan daya sebesar 598.62 watt. [1].

Proses pengurangan kadar $\mathrm{CO}_{2}$ yang terkandung dalam biogas dengan menggunakan media $\mathrm{Ca}(\mathrm{OH})_{2}$ atau endapan batu kapur, kemudian direaksikan dengan $\mathrm{CO}_{2}$ maka akan membentuk $\mathrm{CaCO}_{3}$ dan $\mathrm{H}_{2} \mathrm{O}$. sedangkan variabel yang akan diteliti adalah pengaruh laju aliran biogas terhadap $\mathrm{CO}_{2}$ yang terserap dan $\mathrm{CH}_{4}$ yang dihasilkan. Absorbsi $\mathrm{CO}_{2}$ dilakukan dengan melewatkan biogas dengan berbagai variasi laju aliran ke dalam $\mathrm{Ca}(\mathrm{OH})_{2}$ pada konsentrasi tertentu. Gas dan $\mathrm{Ca}(\mathrm{OH})_{2}$ akan saling kontak dan terjadi reaksi kimia. Tiap interval 2 menit gas yang keluar absorber dideteksi dengan biogas tester untuk dianalisa $\mathrm{CO}_{2}$ yang terserap dan $\mathrm{CH}_{4}$ yang dihasilkan. Selanjutnya dilakukan pengujian pada unjuk kerja motor bakar dengan berbagai variasi putaran mesin, dari hasil analisa didapatkan bahwa rata-rata gas $\mathrm{CO}_{2}$ dapat terserap semuanya pada semua variasi laju aliran biogas (5 It/menit. $10 \quad$ It/menit dan 15 It/menit). Sedangkan $\mathrm{CH}_{4}$ yang dihasilkan paling banyak pada laju aliran biogas 10
It/menit yaitu 91\% diikuti laju aliran $5 \mathrm{lt} /$ menit yakni $76.2 \%$ serta laju aliran $15 \mathrm{lt} /$ menit yakni $72 \%$. Sedangkan pemakaian biogas paling hemat didapati pada pemurnian variasi 2 , yakni rata-rata sebesar $0.235 \mathrm{~kg} / \mathrm{jam}$. Kenaikkan daya efektif terbesar didapat pada variasi 2 dengan kenaikkan daya efektif ratarata terhadap biogas yang belum dimurnikan sebesar $20.7 \%$, sedangkan biogas dengan pemurnian variasi 2 didapat penurunan SFCE rata-rata terhadap biogas yang belum dimurnikan sebesar 32.3\%. [2].

Gas $\mathrm{CO}_{2}$ dalam biogas perlu dihilangkan karena gas tersebut dapat mengurangi nilai kalor pembakaran biogas. Selain itu, kandungan gas karbon dioksida $\left(\mathrm{CO}_{2}\right)$ dalam biogas cukup besar yaitu sekitar $30-45 \%$ sehingga nilai kalor pembakaran biogas akan berkurang cukup besar. Nilai kalor pembakaran gas metana murni pada tekanan 1 atm dan temperatur $15,5^{\circ} \mathrm{C}$ yaitu $9100 \mathrm{Kkal} / \mathrm{m}^{3}$ (12.740 Kkal/kg). Sedangkan nilai kalor pembakaran biogas sekitar 4.800 $6.900 \mathrm{Kkal} / \mathrm{m} 3(6.720-9660 \mathrm{Kkal} / \mathrm{kg})$. [3].

Penggunaan arang aktif sebagai absorber gas $\mathrm{CO}_{2}$ dengan karbon aktif berukuran 6 mesh, 10 mesh dan 14 mesh dalam kolom adsorpsi berukuran tinggi 180 $\mathrm{cm}$, dan diameter kolom 3,75 cm. Ukuran karbon aktif yang memberikan hasil terbaik adalah karbon aktif berukuran 14 mesh dengan effisiensi removal $\mathrm{CO}_{2}$ optimum $59,61 \%$, dengan kecepatan biogas masuk absorber $1000 \mathrm{ml} /$ menit, kandungan gas $\mathrm{CO}_{2}$ masuk $=18,42 \%$ volume, $\mathrm{CH}_{4}$ masuk = $76,32 \%$ volume dan gas $\mathrm{CO}_{2}$ keluar pada posisi kesetimbangan $=7,44 \%$ volume, $\mathrm{CH}_{4}$ keluar pada posisi kesetimbangan $=69,99 \%$ volume. Biogas yang dihasilkan dalam penelitian ini mempunyai komposisi $\mathrm{CH}_{4}=$ $76,32 \%, \mathrm{CO}_{2}=18,42 \%, \mathrm{NH}_{3}=1,62 \%$, dan $\mathrm{H}_{2} \mathrm{~S}=0,28 \%$. [4]

Proses pemurnian dan pengemasan bertekanan biogas dan aplikasinya pada proses pembangkitan energi listrik dan pengganti bahan bakar fosil. Menunjukkan hasil pemurnian biogas mendekati $100 \% \mathrm{CH}_{4}$ dengan tingkat efisiensi hasil listrik dan pembakaran pada mesin mobil mencapai 97 \%. Bajracharya (2009) telah melakukan pemurnian biogas dan peningkatan tekanan dalam sistem penyimpanannya, memperlihatkan tingkat efisiensi pemanasan meningkat sampai $97 \%$ Hal ini menunjukkan keberhasilan pemurnian biogas dengan menggunakan $\mathrm{CaO}, \mathrm{Ca}(\mathrm{OH})_{2}$ dan $\mathrm{NH}_{4} \mathrm{OH}$ sebagai penyerap $\mathrm{CO}_{2}$ serta penyerap gas $\mathrm{H}_{2} \mathrm{~S}$. [5]. 


\section{METODE PENELITIAN}

Metode penelitian yang akan digunakan untuk mencapai tujuan penelitian yaitu melakukan pengujian engine peformance yaitu untuk mengetahui pengaruh $\mathrm{H}_{2} \mathrm{~S}$ dalam biogas terhadap unjuk kerja motor bakar, dilihat dari putaran mesin (1500, 2500, 3500 dan 4500 rpm) dan kehalusan putaran mesin, tahap ini dilakukan di laboratorium konversi energi.

Bahan utama yang dibutuhkan dalam penelitian ini adalah biomassa dari limbah rumah tangga dan limbah peternakan, selanjutnya campurkan limbah biomassa dan air dengan perbandingan $1: 1$, diaduk sampai larut. Campuran tersebut dimasukkan ke dalam tangki penampung (digester). Kemudian semua saluran dan lubang ditutup agar tidak ada udara yang masuk ke dalam sistem. Selanjutnya, campuran kotoran dengan air didiamkan selama $\pm 3-4$ minggu sehingga terbentuk biogas. Penelitian dilanjutkan dengan menguji bahan bakar biogas dalam unjuk kerja motor bakar, dilihat dari putaran mesin $(1500,2500,3500$ dan $4500 \mathrm{rpm})$ dan kehalusan putaran mesin (Gaya pengereman, fuel consumption). Adapun variabel yang dicatat adalah besarnya gaya pengereman dan konsumsi bahan bakar selama dua menit. Pengujian dilakukan pada engine dengan cara menginjeksikan biogas melalui intake manifold dengan menggunakan konversion kit, sedangkan karburator disini hanya berfungsi untuk mengatur suplai udara ke dalam ruang pembakaran.

Sedangkan variabel - variabel yang dipilih antara lain : variabel tetap : Komposisi biogas yang terdiri dari campuran gas - gas $\mathrm{CH}_{4}, \mathrm{CO}_{2}, \mathrm{H}_{2} \mathrm{~S}, \mathrm{H}_{2} \mathrm{O}$ dan lain - lain , Temperatur operasi (Top) : Pada suhu kamar $\left(30^{\circ} \mathrm{C}\right)$. Serta untuk variabel Berubah : putaran mesin : 1500, 2500, 3500 dan 4500 rpm.

Adapun rangkaian alat pengujian peformance engine adalah sebagai berikut,

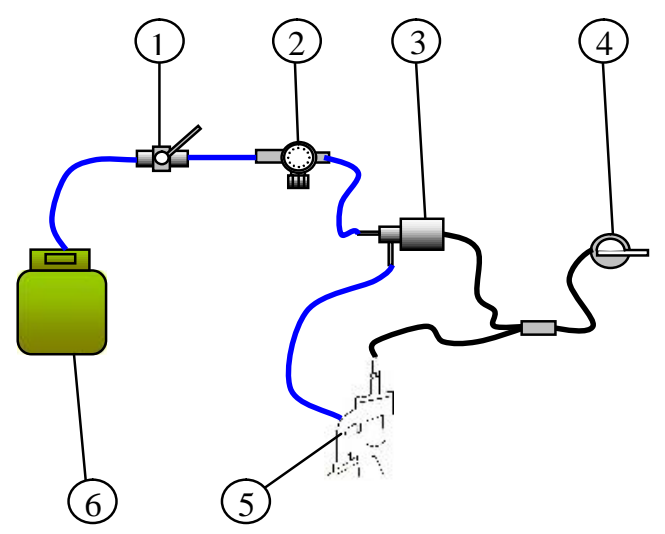

Keterangan :

1. Katup manual

2. Katup regulator

3. Katup throttle

4. Pengatur gas pada engine (pedal gas)

5. Intake manifold (letaknya antara carburator dengan ruang pembakaran pada engine)

6. Biogas yang telah termurnikan dalam tabung

\section{HASIL DAN PEMBAHASAN}

Pada grafik hubungan antara putaran mesin dengan torsi (grafik 4.3) terlihat bahwa torsi yang dihasilkan oleh mesin meningkat seiring dengan meningkatnya putaran mesin, keadaan ini timbul sebagai konsekuensi dari gaya pengereman yang digunakan untuk melawan gaya sentrifugal dari poros mesin yang berputar semakin besar seiring dengan perubahan putaran mesin yang semakin meningkat. Hal ini diikuti juga dengan semakin meningkat putaran mesin dari suatu motor bakar akan memberikan dampak pada semakin besar pula gaya pengereman yang dibutuhkan untuk melawan gaya sentrifugal dari poros mesin yang berputar (grafik 4.1). Dalam prakteknya, torsi dari mesin berguna untuk mengatasi hambatan sewaktu kendaraan jalan menanjak, atau waktu mempercepat laju kendaraan (otomotif), sedangkan pada generator listrik berguna untuk mengatasi hambatan sewaktu beban daya meningkat.

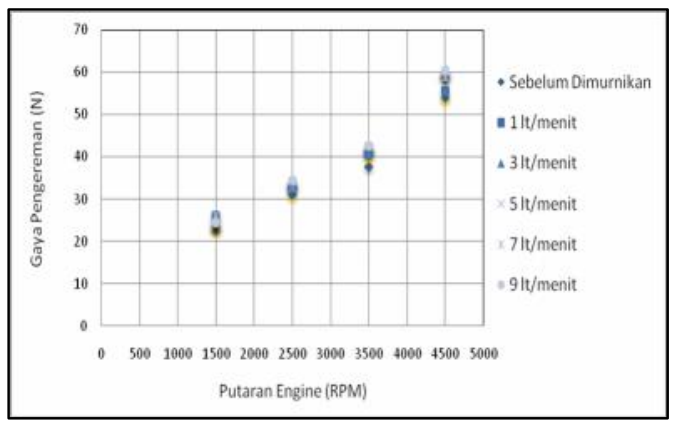

Grafik 4.1. hubungan anatara putaran engine terhadap gaya pengereman 


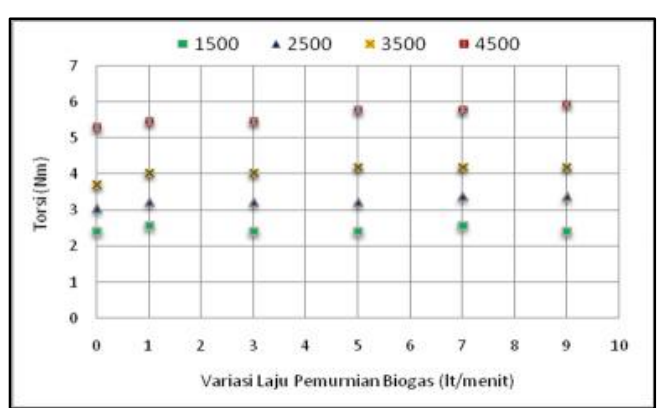

Grafik 4.2. hubungan anatara variasi laju pemurnian biogas terhadap torsi

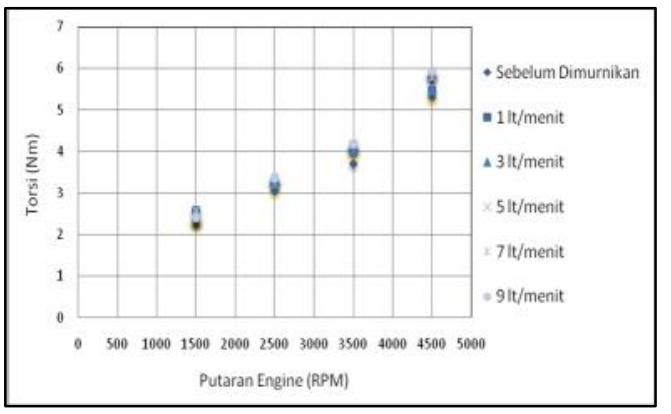

Grafik 4.3. hubungan anatara putaran engine terhadap torsi

Berdasarkan pada data hasil penelitian, diperoleh hubungan antara variasi laju pemurnian biogas dengan torsi (grafik 4.2) menunjukan bahwa perubahan kadar $\mathrm{H}_{2} \mathrm{~S}$ tidak menunjukkan pengaruh yang signifikan terhadap torsi yang dihasilkan oleh engine, untuk berbagai variasi perlakuan menunjukkan nilai torsi yang dihasilkan engine hampir mendekati sama. Hal ini dapat terjadi karena kadar metan dalam biogas untuk berbagai variasi perlakuan memiliki kadar yang hampir sama besarnya, padahal kadar metan yang terkandung dalam bioagas sangat berperan besar terhadap kemampuan suatu engine. Sedangkan kadar $\mathrm{H}_{2} \mathrm{~S}$ hanya berpengaruh terhadap korosi pada material engine.

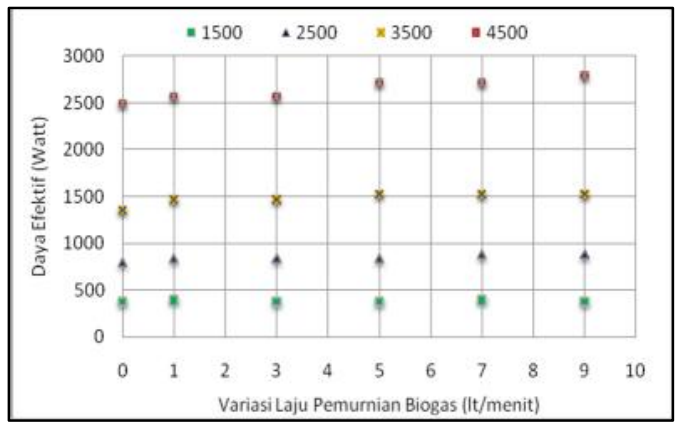

Grafik 4.4. hubungan anatara variasi laju pemurnian biogas terhadap daya efektif

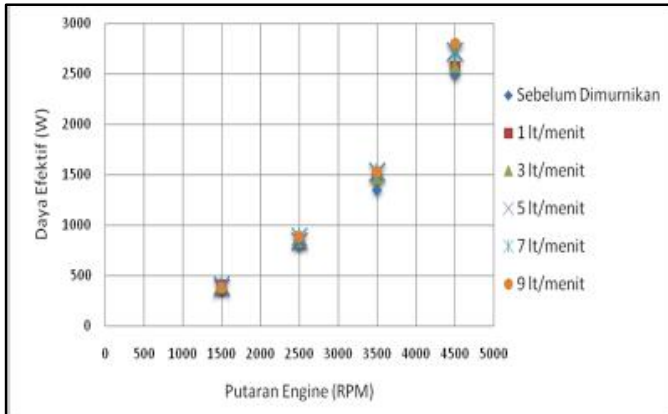

Grafik 4.5. hubungan anatara putaran engine terhadap daya efektif

Berdasarkan pada data hasil penelitian, diperoleh hubungan antara variasi laju pemurnian biogas dengan daya efektif (grafik 4.4) menunjukan bahwa perubahan kadar $\mathrm{H}_{2} \mathrm{~S}$ tidak menunjukkan pengaruh yang signifikan terhadap daya efektif yang dihasilkan oleh engine, untuk berbagai variasi perlakuan menunjukkan nilai daya efektif yang dihasilkan engine hampir mendekati sama. Hal ini dapat terjadi karena kadar metan dalam biogas untuk berbagai variasi perlakuan memiliki kadar yang hampir sama besarnya, padahal kadar metan yang terkandung dalam bioagas sangat berperan besar terhadap unjuk kerja suatu engine.

Pada grafik hubungan antara putaran mesin dengan daya efektif (grafik 4.5) terlihat bahwa daya efektif yang dihasilkan oleh mesin meningkat seiring dengan meningkatnya putaran mesin, hal ini terjadi dikarenakan pada putaran mesin yang semakin tinggi maka torsi yang terjadi akan semakin besar pula. Sedangkan daya efektif mempunyai hubungan erat dengan torsi, jika torsi dikalikan dengan putaran poros engkol (putaran mesin) maka akan didapatkan daya poros atau daya efektif. Sehingga jika torsi dari suatu mesin meningkat besarnya maka secara tidak langsung daya efektif yang terjadi akan meningkat pula.

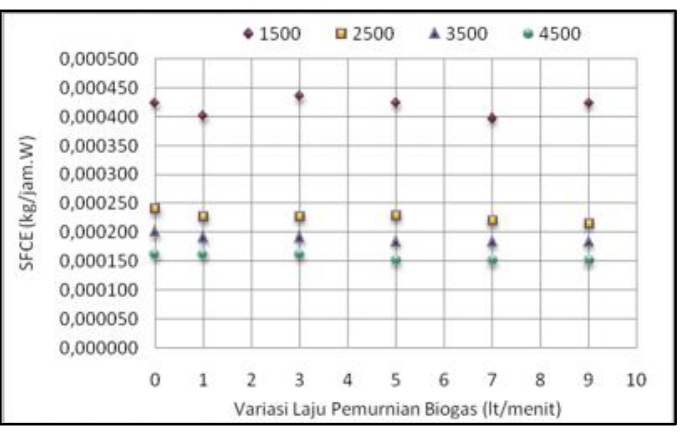

Grafik 4.6. hubungan anatara variasi laju pemurnian biogas terhadap SFCE 


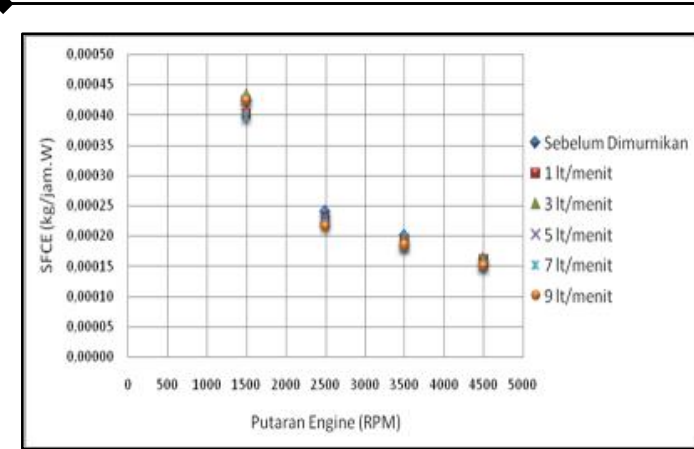

Grafik 4.7. hubungan anatara putaran engine terhadap SFCE

Berdasarkan pada data hasil penelitian, diperoleh hubungan antara variasi laju pemurnian biogas dengan SFCE (grafik 4.6) menunjukan bahwa perubahan kadar $\mathrm{H}_{2} \mathrm{~S}$ tidak menunjukkan pengaruh yang signifikan terhadap SFCE yang dihasilkan oleh engine, untuk berbagai variasi perlakuan menunjukkan nilai SFCE yang dihasilkan engine hampir mendekati sama untuk putaran mesin yang sama. Hal ini dapat terjadi karena kadar metan dalam biogas untuk berbagai variasi perlakuan memiliki kadar yang hampir sama besarnya sehingga konsumsi biogas yang terpakai per jam untuk menghasilkan setiap kWatt daya poros atau daya efektif untuk putaran yang sama pada suatu engine hampir mendekati sama,.

Pada grafik hubungan antara putaran mesin dengan SFCE (grafik 4.7) terlihat bahwa specific fuel consumption efektif yang diperlukan oleh mesin menurun seiring dengan meningkatnya putaran mesin, hal ini terjadi dikarenakan pada putaran mesin yang semakin tinggi maka konsumsi bahan bakar yang terpakai per jam untuk menghasilkan setiap kW daya poros atau daya efektif semakin sedikit. Sedangkan untuk fuel consumption akan semakin naik seiring dengan meningkatnya putaran mesin (grafik 5.8), hal ini menunjukkan bahwa semakin tinggi putaran mesin suatu motor bakar maka akan diikuti semakin besar fuel consumption, meskipun fuel consumption naik tetapi diikuti juga dengan kenaikkan daya poros atau daya efektif.

\section{KESIMPULAN}

Dari hasil pembahasan dapat diambil beberapa kesimpulan sebagai berikut:

1. Perubahan kadar $\mathrm{H}_{2} \mathrm{~S}$ tidak menunjukkan pengaruh yang signifikan terhadap torsi dan daya efektif yang dihasilkan oleh engine.
2. Perubahan kadar $\mathrm{H}_{2} \mathrm{~S}$ tidak menunjukkan pengaruh yang signifikan terhadap konsumsi bahan bakar suatu mesin untuk putaran yang sama pada berbagai variasi pengujian.

3. Daya efektif yang dihasilkan oleh engine meningkat seiring dengan meningkatnya putaran mesin.

\section{SARAN}

Untuk mengembangkan penelitian selanjutnya, maka perlu diperhatikan saran berikut ini yakni perlu dilakukan penelitian lebih lanjut tentang pengaruh $\mathrm{H}_{2} \mathrm{~S}$ yang terkandung dalam biogas terhadap tingkat korosif pada material engine.

\section{DAFTAR PUSTAKA}

[1] Rudy Sutanto dan Tohrirudin, 2007, "Pengolahan jerami padi sebagai bahan baku pembuatan biogas"

[2] Rudy sutanto dan Arif Mulyanto, 2012, "Pengembangan Energi Terbarukan Dengan Optimalisasi Pemanfaatan Biogas Sebagai Sumber Energi Penggerak Generator Listrik Berbasis Absorbsi Gas Carbondioksida", Laporan Akhir Penelitian Hibah STRANAS DIKTI.

[3] Harasimowicz, M., P. Orluk , G Zakrzewska-Trznadel and A.G. Chmielewski, Application of Polyimide Membranes for Biogas Purification and Enrichment, Journal of Hazardous Materials, 2007, vol. 144, pp. $698-702$.

[4] Abdul kareem, A. S., (2003). Refining Biogas Produced from Biomass: An Alternative to Cooking Gas, http://www.ima-eu.org/en/usestext.htm, (tersedia on-line) 24 Oktober 2009

[5] Ofori dan Kwofie (2009), Water Scrubbing: A Betterr option for purification and Biogas storage, Journal World Applied Science (Special issue for Environment), 122-125 